\title{
Factors Influencing Interns' Satisfaction with the Internship Training Programme Offered at Saudi Medical Schools
}

*Ahmed Al Kuwaiti ${ }^{1,2}$ and Arun V. Subbarayalu ${ }^{3}$

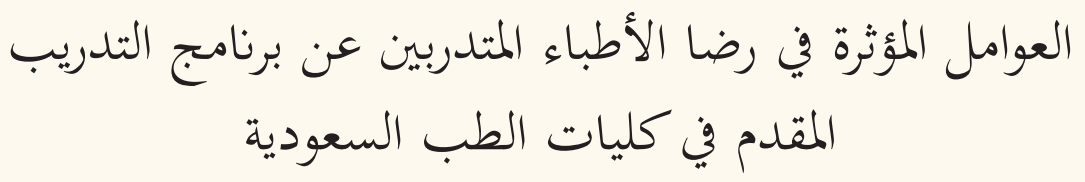

أحمد الكويتي و آرون فيجاي سُويَّارايالو

ABSTRACT: Objectives: This study aimed to assess the perceptions of medical interns with regards to the internship training programme offered at Saudi medical schools and to explore factors influencing their overall satisfaction with this progamme. Methods: This exploratory study was conducted at four medical schools in Saudi Arabia between July 2017 and June 2018. All medical interns undergoing internship training at the selected medical schools during the 2017-2018 academic year were invited to participate in the survey. A questionnaire covering 10 internship dimensions and including a total of 76 items and one global item was designed to assess the medical interns' satisfaction with the training programme. Results: A total of 295 interns returned completed questionnaires (response rate: 92\%). Overall, the interns' satisfaction with all 10 internship dimensions was high (mean score: $\geq 3.6$ ). A multiple regression analysis indicated that various factors were significant predictors of medical interns' overall satisfaction with the internship training programme, including orientation, training site services, supervision, relationships with their superiors and hospital activities $(P<0.050$ each). Conclusion: Medical interns were highly satisfied with the internship training programme offered at Saudi medical schools, with various factors found to significantly influence overall satisfaction. The findings of this study may help policymakers in Saudi Arabia to improve the internship training programme so as to ensure medical interns' overall satisfaction and potentially improve their learning outcomes and clinical training.

Keywords: Undergraduate Medical Education; Internship and Residency; Attitudes; Clinical Competence; Saudi Arabia.

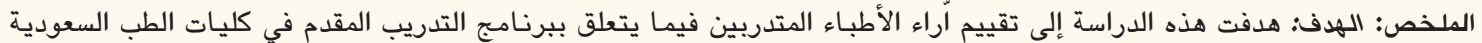

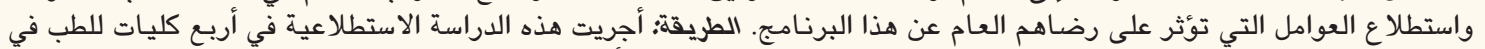

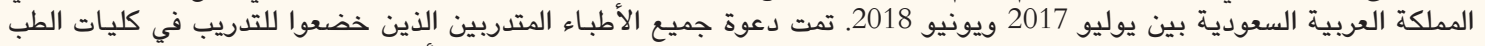

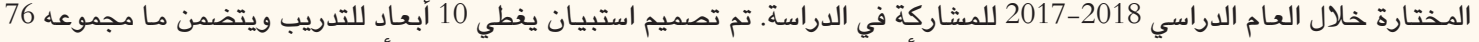

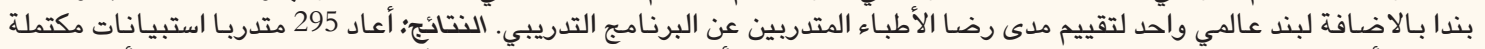

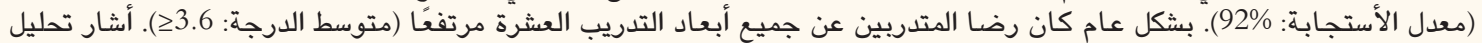

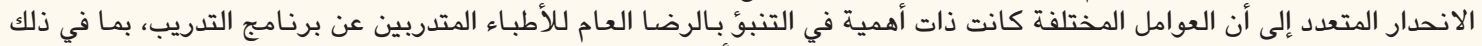

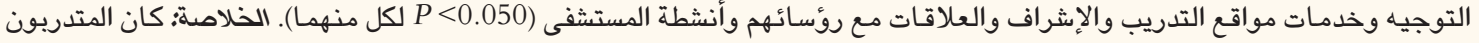

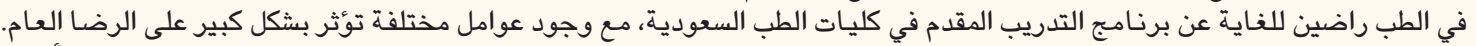

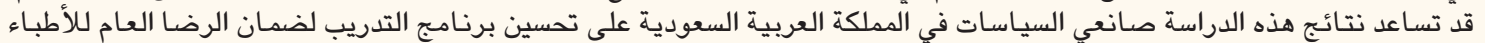

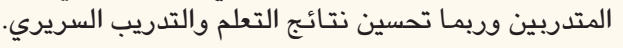

الكلمات المفتاحية؛ التعليم الطبي الجامعي؛ التدريب والإقامة الطبية؛ المواقف؛ الكفاءة السريرية؛ المملكة العربية السعودية.

\section{Advances IN KNOWLedge}

This study identified factors influencing medical interns' satisfaction with the internship training programme offered by medical schools in Saudi Arabia.

In addition, it also highlighted strategies to help academic medical centres to enhance the quality of this programme.

\section{Application to Patient Care}

Understanding how internship training programmes are perceived by medical interns is essential to improving these programmes. Satisfied medical interns are more likely to develop crucial skills and gain confidence in medical practice, thereby better serving patients in the future. 
A MEDICAL INTERNSHIP TRAINING PROGRAMME is an essential element of undergraduate medical education and should be designed in such a way as to enhance the knowledge and skills of interns in clinical practice. ${ }^{1-3}$ In Saudi Arabia, internship training is an integral component of an undergraduate medical degree in which medical students are provided with the opportunity to apply their knowledge and skills to real-life clinical settings after completing their final year of medical school. ${ }^{4,5}$ This programme aims to deliver supervised clinical experience in a wide range of specialties, thereby allowing interns to gain necessary knowledge, skills and attitudes and develop appropriate medical ethics and practices. ${ }^{6}$

The Saudi internship training programme extends over 12 months and consists of both core as well as elective rotations. 5,6 The former involves two months of mandatory training in each of certain required specialties, including internal medicine, obstetrics and gynaecology, general surgery and paediatrics, followed by one-month rotations in emergency medicine and family medicine. The remaining two months are dedicated to an elective rotation in any chosen specialty. ${ }^{5,6}$ Interns train at hospitals recognised by the Saudi Commission for Health Specialties and take part in various activities, including assessing patients, preparing case records and follow-up notes and ordering investigations under the supervision of departmental faculty. ${ }^{6}$ These activities are expected to improve the interns' clinical knowledge and skills and give them the opportunity to treat patients in a supervised environment. ${ }^{7}$

Feedback from medical interns is essential to assess their perceptions of internship training programmes and to identify any deficits, thereby helping to improve the quality of their medical education. Various international researchers have studied factors influencing medical interns' satisfaction with internship training programmes conducted in hospital settings. ${ }^{8-11}$ Sein and Tombo revealed that various factors were associated with effective medical intern training at a hospital in South Africa, including the quality of supervisors, effective supervision, opportunities for learning, learning environment, support system, personal characteristics and workload. ${ }^{9}$ Similarly, Heidarnia and Yasin studied medical interns' satisfaction in Iran using a SERVQUAL model assessing five dimensions (reliability, tangibility, responsibility, assurance and empathy). ${ }^{10}$ Salari et al. also assessed medical interns' satisfaction with the quality of clinical education in teaching hospitals in Iran using six dimensions (familiarity with teaching objectives, clinical training methods, evaluation methods, equipment and clinical facilities, ability to perform acquired clinical skills and teachers' theoretical and practical skills). ${ }^{11}$

In Saudi Arabia, Abdulghani et al. assessed self-perceived stress among medical interns at three universities. ${ }^{4}$ In addition, Alshahrani et al. explored the most influential factors affecting Saudi medical students and their choice of future specialty. ${ }^{12}$ Swaid et al. revealed the perceptions of interns with regards to the medical internship programme offered at a university, including the interns' prior expectations of training and their opinions on the orientation programme, training in various specialties and level of preparedness. ${ }^{7}$ However, this study did not focus on factors influencing medical interns' satisfaction with the programme. The researchers suggested that there was a need to explore in-depth dimensions of the internship training programme offered in Saudi Arabia.?

To the best of the authors' knowledge, no previous studies have assessed factors influencing medical interns' satisfaction with the internship training programme offered at medical schools in Saudi Arabia. Hence, this study aimed to measure medical interns' perceptions of the internship training programme offered at Saudi medical schools and to explore factors influencing their overall satisfaction with this programme.

\section{Methods}

This exploratory study was conducted at four medical schools in Saudi Arabia between July 2017 and June 2018. All medical interns in the 2017-2018 academic year undergoing internship training at the Imam Abdulrahman Bin Faisal University (IAU) in Dammam, the King Saud University (KSU) in Riyadh, King Abdulaziz University (KAU) in Jeddah and King Khalid University (KKU) in Abha were eligible for inclusion in the study. A self-structured questionnaire was developed to assess the medical interns' perceptions of the internship training programme offered by Saudi medical schools. The questionnaire was developed based on the results of a literature review and after conducting a series of brainstorming sessions with medical education specialists in various Saudi medical schools. ${ }^{9-11}$ Paper copies of the survey were distrubted to all medical interns at the selected Saudi medical schools at the end of their internship. All participants were requested to complete and return the questionnaire within a stipulated time frame.

The questionnaire included 76 items covering 10 dimensions of the internship programme and one global item to determine overall satisfaction. 
Table 1: Reliability of internship dimensions included in a survey assessing medical interns' satisfaction with the internship training programme offered at Saudi medical schools

\begin{tabular}{lcc|} 
Dimension & $\begin{array}{c}\text { No. of } \\
\text { items }\end{array}$ & $\begin{array}{c}\text { Cronbach's alpha } \\
\text { coefficient }\end{array}$ \\
\hline Orientation & 5 & 0.937 \\
$\begin{array}{l}\text { Internship programme } \\
\text { objectives }\end{array}$ & 2 & 0.951 \\
$\begin{array}{l}\text { Learning opportunities } \\
\text { Clinical training }\end{array}$ & 15 & 0.965 \\
$\begin{array}{l}\text { Training site services } \\
\text { Working conditions }\end{array}$ & 9 & 0.963 \\
Supervision & 7 & 0.968 \\
$\begin{array}{l}\text { Relationship with } \\
\text { superiors }\end{array}$ & 6 & 0.931 \\
Hospital activities & 7 & 0.970 \\
Performance evaluation & 2 & 0.950 \\
\end{tabular}

The dimensions comprised orientation (five items), internship programme objectives (two items), learning opportunities (15 items), clinical training (11 items), training site services (nine items), working conditions (seven items), supervision (12 items), relationship with superiors (six items), hospital activities (seven items) and performance evaluation (two items). Each dimension was designated as a factor influencing the overall satisfaction of the medical interns. Respondents were requested to indicate their level of agreement with the items in each dimension on a five-point Likert scale, with responses scored from 1 (strongly disagree) to 5 (strongly agree).
The reliability and validity of the questionnaire was assessed [Table 1]. Overall, the Cronbach's alpha coefficient of the survey was 0.99 , indicating that the degree to which the survey items measured the concept being assessed was excellent. ${ }^{13}$ In addition, confirmatory factor analysis was performed utilising the principal component method to determine the construct validity of the survey. Various statistical criteria, including the Kaiser-Meyer-Olkin (KMO) value $(\mathrm{KMO}=0.952)$ and Bartlett's test of sphericity (32490.923; $P<0.050$ ), demonstrated that the raw data were appropriate for the analysis. All of the items in the questionnaire had $\mathrm{KMO}$ values of $>0.60$, indicating that the quality of measurement was satisfactory. From the original 76 items used in the factor analysis, 10 dimensions were derived using Kaiser criterion and varimax rotation. These 10 dimensions together accounted for $70.9 \%$ of the total variation from the initial data.

Data analysis was performed using the Statistical Package for the Social Sciences (SPSS), Version 20.0 (IBM Corp., Armonk, New York, USA). Each dimension of the survey was graded according to performance criteria reported by $\mathrm{Al}$ Rubaish and $\mathrm{Al}$ Rubaish on the basis of the level of agreement of the medical interns to the survey items..$^{14,15}$ Accordingly, each dimension was graded as either high-quality (mean scores of $\leq 3.6$ ), acceptable (mean scores of 2.6-3.6) or improvement required (mean scores of $>2.6$ ). Subsequently, a multiple regression analysis was conducted to assess the influence of the 10 internship dimensions (independent variables) on overall satisfaction (dependent variable). A $P$ value of $<0.050$ was deemed statistically significant.

Table 2: Agreement with internship dimensions among medical interns undergoing internship training at Saudi medical schools $(\mathrm{N}=295)$

\begin{tabular}{lccccc} 
Dimension & \multicolumn{3}{c}{ Response, $\mathbf{n}$ (\%) } & Strongly agree \\
& $\begin{array}{l}\text { Strongly } \\
\text { disagree }\end{array}$ & Disagree & Neutral & Agree & $75(25.4)$ \\
Orientation & $8(2.7)$ & $28(9.5)$ & $90(30.5)$ & $94(31.9)$ & $73(24.7)$ \\
Internship programme objectives & $10(3.4)$ & $24(8.1)$ & $87(29.5)$ & $101(34.3)$ & $48(16.3)$ \\
Learning opportunities & $8(2.7)$ & $19(6.4)$ & $112(38)$ & $108(36.6)$ & $56(19)$ \\
Clinical training & $10(3.3)$ & $12(4.1)$ & $107(36.3)$ & $110(37.3)$ & $64(21.8)$ \\
Training site services & $14(4.7)$ & $19(6.4)$ & $98(33.2)$ & $100(33.9)$ & $54(18.3)$ \\
Working conditions & $8(2.7)$ & $24(8.1)$ & $110(37.3)$ & $99(33.6)$ & $58(19.7)$ \\
Supervision & $10(3.4)$ & $17(5.8)$ & $101(34.2)$ & $109(36.9)$ & $76(25.8)$ \\
Relationship with superiors & $12(4.1)$ & $15(5.1)$ & $95(32.2)$ & $97(32.9)$ & $71(24.1)$ \\
Hospital activities & $13(4.4)$ & $15(5.1)$ & $96(32.5)$ & $100(33.9)$ & $81(27.5)$ \\
Performance evaluation & $9(3)$ & $27(9.2)$ & $96(32.5)$ & $82(27.8)$ & $61(20.7)$ \\
Overall satisfaction & $18(6.1)$ & $19(6.4)$ & $89(30.2)$ & $108(36.6)$ &
\end{tabular}


Table 3: Mean satisfaction scores per internship dimension among medical interns undergoing internship training at Saudi medical schools $(\mathrm{N}=295)$

\begin{tabular}{|c|c|c|c|}
\hline Dimension & $\begin{array}{l}\text { No. of } \\
\text { items }\end{array}$ & $\begin{array}{l}\text { Mean } \\
\text { score }\end{array}$ & Grade \\
\hline Orientation & 5 & 3.7 & High-quality \\
\hline $\begin{array}{l}\text { Internship } \\
\text { programme objectives }\end{array}$ & 2 & 3.7 & High-quality \\
\hline $\begin{array}{l}\text { Learning } \\
\text { opportunities }\end{array}$ & 15 & 3.6 & High-quality \\
\hline Clinical training & 11 & 3.6 & High-quality \\
\hline Training site services & 9 & 3.6 & High-quality \\
\hline Working conditions & 7 & 3.6 & High-quality \\
\hline Supervision & 12 & 3.6 & High-quality \\
\hline $\begin{array}{l}\text { Relationship with } \\
\text { superiors }\end{array}$ & 6 & 3.7 & High-quality \\
\hline Hospital activities & 7 & 3.7 & High-quality \\
\hline $\begin{array}{l}\text { Performance } \\
\text { evaluation }\end{array}$ & 2 & 3.7 & High-quality \\
\hline Overall satisfaction & 1 & 3.6 & High-quality \\
\hline
\end{tabular}

This study was conducted according to the guidelines of the Deanship of Scientific Research at IAU. Ethical approval was obtained from the Deanship of Scientific Research, Imam Abdulrahman Bin Faisal University, Al-Khobar, Saudi Arabia. All respondents provided written informed consent prior to participating in the survey.

\section{Results}

A total of 295 medical interns took part in the survey (response rate: 92\%). Of these, 174 (59\%) were male and 121 (41\%) were female. All respondents were of Saudi nationality. In terms of distribution, 88 (29.8\%), 80 (27.1\%), 76 (25.8\%) and 51 (17.3\%) of the medical interns were enrolled at IAU, KSU, KAU and KKU, respectively.

Table 2 shows the level of agreement reported by the medical interns for each internship dimension. A few respondents strongly disagreed with items relating to training site services (4.7\%), relationship with superiors (4.1\%), hospital activities (4.4\%) and overall satisfaction (6.1\%). Just over one-third of respondents were neutral towards items relating to learning opportunities (38\%), clinical training (36.3\%) and working conditions (37.3\%). The majority of the respondents $(>55 \%)$ agreed or strongly agreed with items in all of the dimensions, apart from learning opportunities (52.9\%) and working conditions (51.9\%). A total of 169 interns (57.3\%) agreed or strongly agreed that they were generally satisfied with the internship training programme.

Based on the mean scores of the interns' responses to the items in each dimension, all of the dimensions were graded as high-quality [Table 3]. However, upon reviewing the mean scores for individual items in the survey, 11 items were graded as acceptable. These items fell under six dimensions, including learning opportunities, training site services, working conditions, supervision, hospital activities and performance evaluation [Table 4].

A multiple regression analysis was applied to assess the influence of each dimension on the medical interns' overall satisfaction with the internship training programme. Overall, the regression model was significant (F value $=60.011 ; P<0.001$ ), with the 10 dimensions of the survey explaining $67.9 \%\left(R^{2}=0.679\right)$ of the total

Table 4: Internship items requiring further improvement based on mean satisfaction scores among medical interns undergoing internship training at Saudi medical schools $(\mathrm{N}=295)$

\begin{tabular}{|c|c|c|c|}
\hline Dimension & Item & Mean score \pm SD & Grade \\
\hline Learning opportunities & $\begin{array}{l}\text { - I was exposed to research opportunities } \\
\text { - The seminars improved my knowledge } \\
\text { - There was sufficient opportunity for skill practice } \\
\text { - There was sufficient time to prepare for postgraduate entrance } \\
\text { examinations } \\
\text { - I am satisfied with the learning opportunities during my } \\
\text { internship }\end{array}$ & $\begin{array}{l}3.3 \pm 1.3 \\
3.5 \pm 1.0 \\
3.5 \pm 1.0 \\
3.5 \pm 1.1 \\
3.5 \pm 1.0\end{array}$ & $\begin{array}{l}\text { Acceptable } \\
\text { Acceptable } \\
\text { Acceptable } \\
\text { Acceptable } \\
\text { Acceptable }\end{array}$ \\
\hline Training site services & - The atmosphere was professional & $3.5 \pm 1.1$ & Acceptable \\
\hline Work conditions & $\begin{array}{l}\text { - The internship training did not overload me psychologically } \\
\text { - Working hours were adequately scheduled to allow time to } \\
\text { prepare for entrance/licensure examinations }\end{array}$ & $\begin{array}{l}3.5 \pm 1.1 \\
3.4 \pm 1.1\end{array}$ & $\begin{array}{l}\text { Acceptable } \\
\text { Acceptable }\end{array}$ \\
\hline Supervision & -The residents were adequately involved in teaching & $3.5 \pm 1.1$ & Acceptable \\
\hline Hospital activities & - I presented cases during morning reports & $3.5 \pm 1.2$ & Acceptable \\
\hline Performance evaluation & - My performance was assessed against learning objectives & $3.5 \pm 1.1$ & Acceptable \\
\hline
\end{tabular}

SD = standard deviation 
Table 5: Factors influencing medical interns' overall satisfaction with the medical internship progamme offered at Saudi medical schools $(\mathrm{N}=295)$

$\begin{array}{lcccc}\text { Variable } & \begin{array}{c}\text { Unstandardised } \beta \text { coefficient } \\ \pm \mathrm{SE}\end{array} & \begin{array}{c}\text { Standardised } \beta \\ \text { coefficient }\end{array} & \text { t-value } & \boldsymbol{P} \text { value } \\ \text { Constant } & -0.040 \pm 0.159 & - & 0.025 & 0.980 \\ \text { Orientation } & 0.147 \pm 0.058 & 0.142 & 2.524 & 0.012^{*} \\ \text { Internship programme objectives } & -0.064 \pm 0.065 & -0.062 & 0.992 & 0.322 \\ \text { Learning opportunities } & 0.158 \pm 0.087 & 0.136 & 1.817 & 0.070 \\ \text { Clinical training } & 0.132 \pm 0.084 & 0.116 & 1.574 & 0.117 \\ \text { Training site services } & 0.141 \pm 0.065 & 0.137 & 2.161 & 0.032^{*} \\ \text { Working conditions } & 0.113 \pm 0.066 & 0.102 & 1.708 & 0.089 \\ \text { Supervision } & 0.367 \pm 0.085 & 0.332 & 4.324 & <0.001^{*} \\ \text { Relationship with superiors } & -0.295 \pm 0.070 & -0.284 & 4.233 & <0.001^{*} \\ \text { Hospital activities } & 0.302 \pm 0.069 & 0.290 & 4.401 & <0.001^{*} \\ \text { Performance evaluation } & -0.003 \pm 0.063 & -0.003 & 0.047 & 0.962\end{array}$

*Significant at $P<0.050$.

variation in overall satisfaction. There was a strong positive relationship between all 10 dimensions and overall satisfaction $(\mathrm{R}$ value $=0.824)$. Moreover, five dimensions were found to significantly influence overall satisfaction, including orientation $(P=0.012)$, training site services $(P=0.032)$, supervision $(P<0.001)$, relationship with superiors $(P<0.001)$ and hospital activities $(P<0.001)$. Based on unstandardised $\beta$ coefficients, the most important predictor was supervision $(\beta=0.367 \pm 0.085)$, followed by hospital activities $(\beta=0.302 \pm 0.069)$, relationship with superiors $(\beta=-0.295$ $\pm 0.070)$, orientation $(\beta=0.147 \pm 0.058)$ and training site services $(\beta=0.141 \pm 0.065)$ [Table 5].

\section{Discussion}

This study assessed the attitudes of medical interns towards and their overall satisfaction with the internship training programme offered at Saudi medical schools. Overall, very few medical interns (4.1-6.1\%) strongly disagreed with items falling under the dimensions of training site services, relationship with superiors, hospital activities and overall satisfaction, while $36.3-38 \%$ were neutral with regards to items under the learning opportunities, clinical training and working conditions dimensions. Overall, 57.3\% of medical interns agreed or strongly agreed that they were satisfied with the internship training programme provided by Saudi medical schools. Contrary to these findings, Yasser et al. found that medical interns at Umm Alqura University in Makkah, Saudi Arabia, were only moderately satisfied with what they had learned during their internship year. ${ }^{16}$ Moreover, in Iran,
Heidarnia and Yasin reported that medical interns at Shahid Beheshti University of Medical Sciences were not satisfied with their internship programme. ${ }^{10}$

In the present study, all of the internship dimensions included in the survey were graded as high-quality, with each dimension receiving a mean Likert score of $\geq 3.6$. In particular, five internship dimensions-orientation, training site services, supervision, relationship with superiors and hospital activities-were identified as significant factors influencing Saudi medical interns' overall satisfaction with the internship training programme. In a recent study, the majority of interns at an Ethiopian medical school reported receiving more orientation during their undergraduate emergency medicine training, a factor which helped them to develop clinical expertise regarding the diagnosis and management of different medical conditions. ${ }^{17}$ In contrast, Mofolo and Botes noted that a lack of orientation and inadequate supervision negatively affected the internship experience of medical interns in South Africa. ${ }^{18}$ In Saudi Arabia, all medical interns must attend an orientation course prior to the commencement of internship training. In addition, Saudi medical schools also provide a mandatory general hospital orientation for medical interns at the beginning of their internship. ${ }^{6}$

Training site services and hospital activities were other significant factors affecting overall satisfaction in the present study. Salari et al. noted that variations between available clinical equipment and facilities and educational plans was one of the reasons for medical interns' dissatisfaction with the quality of their clinical education. ${ }^{11}$ Likewise, library facilities are also essential 
since half of the questions posed during hospital rounds are usually answered by medical interns using textbooks and database searches. ${ }^{19}$ Yasser et al. noted that hospital activities such as morning meetings and seminars can improve Saudi medical interns' satisfaction, although further studies are required to confirm whether this recommendation is effective. ${ }^{16}$

Previous studies have identified the quality of supervisors and effective supervision as factors associated with medical interns' satisfaction with internship programmes. ${ }^{9,20}$ This is in accordance with the results observed in the current study, which indicated that supervision was the most crucial factor influencing the medical interns' overall satisfaction with their internship training programme. The relationship between interns and their superiors is another important factor and can positively or negatively shape the entire internship experience. Unfortunately, Yasser et al. reported that resident supervisors constituted the most common source of abuse and mistreatment of interns at Umm Alqura University. ${ }^{16}$ Iftikhar et al. also observed that abuse and maltreatment was not uncommon among interns at KAU. ${ }^{21}$ On the other hand, resident supervisors have been found to contribute significantly to the interns' learning process in various countries. ${ }^{16,22}$

In the present study, 11 items in the survey received acceptable grades according to their mean Likert scores, indicating that there is scope for improvement. Accordingly, the following strategies are suggested as methods of further enhancing medical interns' satisfaction and improving the quality of the internship training programme offered at Saudi medical schools. In particular, medical interns did not wholly agree with the statement that the seminars they received enhanced their knowledge. In teaching hospitals in Saudi Arabia, most seminars are carried out under the umbrella of the Department of Medical Education and the Directorate of Academic Affairs \& Training and focus primarily on medical students rather than interns. Therefore, seminars need to be designed which focus specifically on enriching the skills of interns. Likewise, medicals schools should teach more clinical hands-on skills for interns regarding the management of complex conditions. Additionally, workshops and training sessions can be conducted to strengthen research-oriented activities, encouraging medical interns' involvement in research and helping them to publish research articles. Furthermore, interns should be included in clinical meetings, with assigned opportunities to present interesting/challenging cases and to receive feedback from residents and consultants.
Scheduled working hours and time management were other areas for improvement in the current study, with some interns feeling that their assigned workload did not leave them sufficient time to prepare for their entrance, licensure or postgraduate examinations. As such, Saudi medical schools should develop and implement a rotation-specific schedule to optimise interns' workload during the internship period. These measures would provide medical interns with sufficient time to prepare for their examinations and could also help to ease the psychological overload reported by some of the interns. Psychosocial support and counselling services should also be offered to help with stress management.

Moreover, Saudi medical schools should take measures to ensure that the internship programme reflects a professional atmosphere-another area requiring improvement-so that interns can enjoy smooth working relations with all hospital staff, patients and their attendants. In addition, the assessment system used to evaluate the performance of the interns needs further strengthening, with welldefined assessment criteria. The interns should be assessed by their direct supervisors at the end of each rotation, with the average of all assessments carried out during the entire internship taken into consideration when calculating the final assessment score.

The findings of this study are limited to the four Saudi medical schools selected for inclusion in the study; as such, further research conducted at other medical schools in Saudi Arabia is recommended to provide more generalised results. Similarly, future studies should assess the influence of gender on Saudi medical interns' perceptions towards internship training. Even though Saudi medical interns perceived their internship training programme to be of high quality in this study, their overall satisfaction was significantly predicted by only five dimensions; as such, further research is warranted to explore reasons as to why the remaining five factors were not predictive.

\section{Conclusion}

Overall, medical interns were highly satisfied with the internship training programme offered at Saudi medical schools. Various internship dimensions, including orientation, training site services, supervision, relationship with superiors and hospital activities, were identified as significant factors influencing overall satisfaction. However, 11 items were identified as requiring improvement. Policymakers in Saudi Arabia should take this feedback into account to further enhance medical interns' satisfaction with the internship training programme. 


\section{CONFLICT OF INTEREST}

The authors declare no conflicts of interest.

\section{FUNDING}

No funding was received for this study.

\section{References}

1. Levine RB, Haidet P, Kern DE, Beasley BW, Bensinger L, Brady DW, et al. Personal growth during internship: A qualitative analysis of interns' responses to key questions. J Gen Intern Med 2006; 21:564-9. https://doi.org/10.1111/j.1525-1497.2006.00383.x.

2. Lam T, Ching L. An exploratory study of an internship program: The case of Hong Kong students. Int J Hosp Manag 2007; 26:336-51. https://doi.org/10.1016/j.ijhm.2006.01.001.

3. Ackerman A, Graham M, Schmidt H, Stern DT, Miller SZ. Critical events in the lives of interns. J Gen Intern Med 2009; 24:27-32. https://doi.org/10.1007/s11606-008-0769-8.

4. Abdulghani HM, Irshad M, Al Zunitan MA, Al Sulihem AA, Al Dehaim MA, Al Esefir WA, et al. Prevalence of stress in junior doctors during their internship training: A cross-sectional study of three Saudi medical colleges' hospitals. Neuropsychiatr Dis Treat 2014; 10:1879-86. https://doi.org/10.2147/NDT.S68039.

5. Saudi Commission for Health Specialties. Medical specialty selection guide for medical graduates. From: www.scfhs.org.sa/ Media/OtherPublications/Documents/Medical\%20Guide\%20 Complete\%2031.3.15.pdf Accessed: Nov 2019.

6. University of Dammam College of Medicine. Internship. From: www.iau.edu.sa/sites/default/files/resources/internship man. pdf Accessed: Nov 2019.

7. Swaid AI, Elhilu AH, Mahfouz MS. Medical internship training in Saudi Arabia: Interns' views and perceptions. Adv Med Educ Pract 2017; 8:121-8. https://doi.org/10.2147/AMEP.S123119.

8. Ziaee V, Ahmadinejad Z, Morravedji AR. An evaluation on medical students' satisfaction with clinical education and its effective factors. Med Educ Online 2004; 9:4365. https://doi.org/10.3 402/meo.v9i.4365.

9. Sein N, Tumbo J. Determinants of effective medical intern training at a training hospital in North West Province, South Africa. African J Health Prof Educ 2012; 4:10-14. https://doi.org/10.71 96/ajhpe.100.

10. Heidarnia MA, Yasin M. An evaluation on medical interns satisfaction in internship course in Shahid Beheshti University of Medical Sciences by SERVQAUL model. Health Educ Health Promot 2013; 1:33-43.
11. Salari A, Moaddab F, Balasi LR, Dadgaran I, Nourisaeed A, Pourali H, et al. Medical interns' satisfaction of clinical education's quality in Rasht hospitals. Educ Res Med Sci 2017; 5:e79207.

12. Alshahrani M, Dhafery B, Al Mulhim M, Alkhadra F, Al Bagshi D, Bukhamsin N. Factors influencing Saudi medical students and interns' choice of future specialty: A self-administered questionnaire. Adv Med Educ Pract 2014; 5:397-402. https://doi.org/10.21 47/AMEP.S69152.

13. George D, Mallery P. SPSS for Windows step by step: A simple guide and reference 11.0 update, 4th ed. Boston, Massachusetts, USA: Allyn \& Bacon, 2002.

14. Al Rubaish A. On the contribution of student experience survey regarding quality management in higher education: An institutional study in Saudi Arabia. J Serv Sci Manage 2010; 3:464-9. https://doi.org/10.4236/jssm.2010.34052.

15. Al Rubaish A, Wosornu L, Dwivedi SN. Appraisal of using global student rating items in quality management in higher education in Saudi Arabian university. iBusiness 2012; 4:1-9. https://doi.org/10.4236/ib.2012.41001.

16. Yasser A, Mutaz A, Baraa A. Medical interns' learning and mistreatment received during the internship year: Are they satisfied? Educ 2016; 6:13-16. https://doi.org/10.5923/j.edu.20160601.03.

17. Beyene T, Tupesis JP, Azazh A. Attitude of interns towards implementation and contribution of undergraduate emergency medicine training: Experience of an Ethiopian medical school. Afr J Emerg Med 2017; 7:108-12. https://doi.org/10.1016/j.aff em.2017.04.008

18. Mofolo N, Botes J. An evaluation of factors influencing perceptual experiences and future plans of final-year medical interns in the Free State, 2013-2014. S Afr Fam Pract 2016; 58:185-91. https://doi.org/10.1080/20786190.2016.1225421.

19. Tannery NH, Foust JE, Gregg AL, Hartman LM, Kuller AB, Worona $\mathrm{P}$, et al. Use of web-based library resources by medical students in community and ambulatory settings. J Med Libr Assoc 2002; 90:305-9.

20. Cannon GW, Keitz SA, Holland GJ, Chang BK, Byrne JM, Tomolo A, et al. Factors determining medical students' and residents' satisfaction during VA-based training: Findings from the VA Learners' Perceptions Survey. Acad Med 2008; 83:611-20. https://doi.org/10.1097/ACM.0b013e3181722e97.

21. Iftikhar R, Tawfiq R, Barabie S. Interns' perceived abuse during their undergraduate training at King Abdul Aziz University. Adv Med Educ Pract 2014; 5:159-66. https://doi.org/10.2147/ AMEP.S62890.

22. Daugherty SR, Baldwin DC Jr, Rowley BD. Learning, satisfaction, and mistreatment during medical internship: A national survey of working conditions. JAMA 1998; 279:1194-9. https://doi.org/10.1 001/jama.279.15.1194. 